\title{
Comparison and Research of Micro-course Teaching and Traditional Teaching Based on APH
}

\author{
Liu Yingxin ${ }^{1}$ Liu Baoyin ${ }^{1}$ \\ Shenyang University
}

\author{
Du juan ${ }^{2}$ \\ Shenyang Normal University
}

\begin{abstract}
With the development and advancement of information and internet technology, Micro-course is more concerned by students and teachers for its short time and refined and essential content. After integrating with the feedback result of the questionnaire by Analytic Hierarchy Process, constructing the evaluation index of the effect of micro-course and traditional teaching, calculating the weight or criteria of the relative index, and comparing and analyzing the teaching effect of micro-course and traditional teaching, this paper concludes that micro-course teaching can arouse student's interest and improve students' learning ability and traditional teaching has advantages in the interaction between teachers and students. This paper also puts forward suggestions on the results of the analysis, which can provide a reference for teacher's teaching methods and students' learning ways.
\end{abstract}

Keywords-Analytic Hierarchy Process; Micro-course teaching; traditional teaching; learning ability

\section{INTRODUCTION}

Article 60 of the National Program for Medium and Longterm Educational Reform and Development (2010-2020) clearly states that teachers should adopt information and internet technology to renew teaching concepts, improve teaching methods, and teaching effectiveness, encourage students to use information means to study actively and independently, and enhance the ability of problem solving by using information technology analysis. The ability to solve problems will speed up the popularization and application [1]. In the traditional teaching process, teachers should improve teaching effect, especially for more abstract and complex knowledge points in the teaching objectives, teachers will try their best to find a variety of ways to impart knowledge, so as to optimize teaching effect. At present, micro-course teaching is widely used in the education field. After the expert's argumentation, teachers' and students' test, integrating with the result of reasonably questionnaire survey, and the teaching effect is compared and evaluated by the analytic hierarchy process (AHP), finally the content of the evaluation is reasonable and the method of evaluation is scientific and rigorous.

\section{RELATED CONCEPT}

\section{A. Analytic Hierarchy Process (AHP)}

Analytic Hierarchy Process was firstly proposed by Saaty T. L.-American Operational research experts in the 1970s, which is a kind of qualitative and quantitative evaluation method suitable for multi-criteria, multi-elements and multilevels ${ }^{[2]}$. The method decomposes the decision-maker's objective problem into several levels and factors, simplifies the very complex system research, compares and judges the importance of various factors, and obtains the weight or criteria of different importance degree of the scheme by simple calculation, which provides a reference for the selection of optimal scheme.

\section{B. Micro-course}

Micro-courses ${ }^{[3]}$ refers to the short-term course within 10 minutes, with a clear teaching objectives and short content, and only focus on one question. In the newest micro-course teaching process, micro-video (made by teacher) teaching for students' autonomous learning has become an indispensable part of students' autonomous learning. Micro-video ${ }^{[4]}$, refers to teaching significance of micro-video resources, which may be shorter just for 30 seconds and is no longer than 20 minutes, with a wide range of content and variety video forms. Microcourse, micro-video and micro-courses are teaching integration of emerging resources of learning content, learning methods and information \& Internet teaching.

\section{ANALYTIC HIERARCHY PROCESS (AHP)}

\section{A. Constructing hierarchy index system}

The paper evaluates teaching effect of micro-course and traditional teaching, objectively reflects the advantages of micro-course and traditional teaching. In order to evaluate the real teaching effect scientifically and reasonably, when designing evaluation system, firstly organized a questionnaire survey for some teachers and students of Normal college through the platform of Wenjuanxing. Among them, 247 valid questionnaires were retrieved, of which teachers and students were the main participants, and the proportion of teachers is $40.9 \%$, the proportion of students is $59.9 \%$, which conforms to characteristic or requirement that students take more proportion. 


\section{1) Factors for teachers' choice of teaching methods}

In the index evaluation system, factors affecting teachers' choice of teaching methods mainly include knowledge comprehension, classroom speech, difficulty explanation and classroom practice. The proportion of the four factors is $87.85 \%, 5.26 \%, 4.05 \%$ and $2.83 \%$ respectively. Knowledge understanding occupies a very important proportion.

\section{2) Factors for students' understanding of knowledge}

In the questionnaire, the main factors designed for students' understanding of knowledge are knowledge extension, learning interest, large number of exercises and rote memorization. The proportion of the four factors is $84.48 \%$,

$14.66 \%, 0.86 \%$ and 0 respectively. It can be seen that students think that expanding existing knowledge can be better to enhance knowledge understanding .

\section{3) Factors for students' interest in learning}

Four factors affecting students' interest were designed: teacher-student communication, teaching illustration and painting, teacher's vivid language and teacher's neat writing. The survey results were $88.79 \%, 3.02 \%, 7.76 \%$ and $0.43 \%$ respectively. According to the data, in the era of rapid development of the Internet, students still think that teacherstudent communication is the main factor of learning interest.

\section{4) Factors for students' comprehensive ability}

Among the factors affecting students' comprehensive ability, learning ability accounted for $89.66 \%$, writing ability accounted for $0.86 \%$, expression ability accounted for $9.05 \%$, and the rest is reading ability. Learning ability occupies an important proportion in the proportion of factors affecting students' comprehensive ability.

\section{B. Establishing a hierarchical construction figure}

The analytic hierarchy process divides the factors involved in decision making into the following categories. The structural system of the problem is described by a hierarchical structure chart, as shown in Fig. 1.

Target layer A--teaching effect; criterion layer B--B1 for Knowledge Comprehension;B2 for Knowledge Extension; B3 for Communication; B4 for Learning Ability; scheme layer C-C1 for Micro-course Teaching, C2 for traditional Teaching.

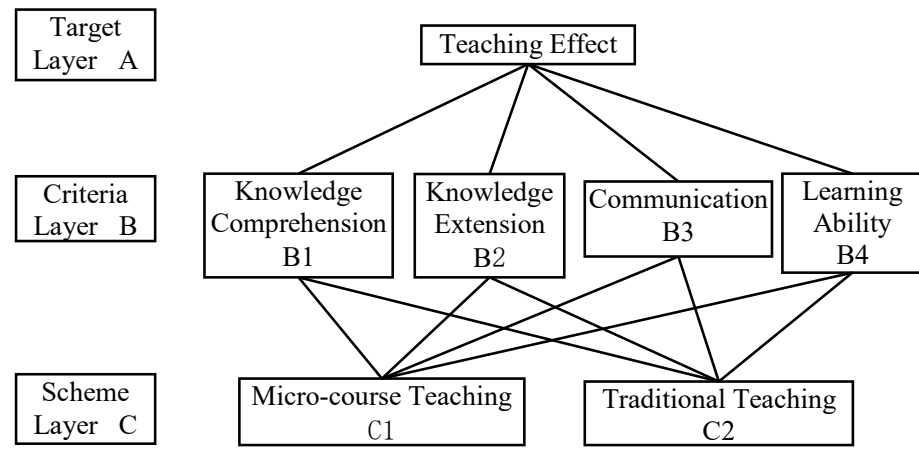

Fig. 1 Hierarchical Construction Figure

\section{Constructing Two-to-Two judgment matrix}

Constructing two-to-two judgment matrix is the most important link in Analytic Hierarchy Process (AHP), and its construction directly affects the success or failure of AHP. By means of the numerical construction of the matrix, people's awareness of the relative importance of various factors can be reflected. When two-to-two judge and compare the matrix, it is determined by the scale method of 1-9. A judgment matrix is a comparison of the relative importance of all the factors in this layer to one of the factors in the upper layer. The elements of the judgment matrix are given by 1-9 scoring scale method proposed by Professor Satie of the University of Pittsburgh, $\mathrm{USA}^{[2]}$. As shown in Table I.

The factors of criterion layer include knowledge understanding, learning ability, teacher-student communication and knowledge extension. At the same time, the construction of a two-to-two matrix is the premise of our overall ranking. For target Layer A, the importance of knowledge understanding is 7 times of knowledge extension. Therefore, in the matrix table, the assignment value is 7 . According to Table I, it can be reflected that knowledge understanding is more important than knowledge extension. In this way, a judgment matrix like table II is constructed.

TABLE I. SCORING SCALE

\begin{tabular}{|c|c|}
\hline Scale & Meaning \\
\hline 1 & The two factors are of equal importance \\
\hline 3 & One of the two factors is slightly more important than the other one. \\
\hline 5 & One of the two factors is obviously more important than the other one. \\
\hline 7 & One of the two factors is strongly important than the other one. \\
\hline 9 & One of the two factors is extremely important than the other one. \\
\hline 24 & The median of the above two adjacent judgments \\
6.8 & \\
\hline
\end{tabular}

TABLE II. TEACHING EFFECT

\begin{tabular}{|c|c|c|c|c|}
\hline & $\begin{array}{c}\text { Knowledge } \\
\text { Comprehension }\end{array}$ & $\begin{array}{c}\text { Knowledge } \\
\text { Extension }\end{array}$ & $\begin{array}{c}\text { Teacher-student } \\
\text { Communication }\end{array}$ & $\begin{array}{c}\text { Learning } \\
\text { Ability }\end{array}$ \\
\hline $\begin{array}{c}\text { Knowledge } \\
\text { Comprehension }\end{array}$ & 1 & 7 & 5 & 3 \\
\hline $\begin{array}{c}\text { Knowledge } \\
\text { Extension }\end{array}$ & $1 / 7$ & 1 & $1 / 3$ & $1 / 5$ \\
\hline $\begin{array}{c}\text { Teacher-student } \\
\text { Communication }\end{array}$ & $1 / 5$ & 3 & 1 & $1 / 3$ \\
\hline Learning Ability & $1 / 3$ & 5 & 3 & 1 \\
\hline
\end{tabular}

D. Calculate the relative weight or criteria between indicators and test consistency.

1) Calculating Relative Weights between Indicators and Verifying Consistency

Firstly, the relative weight value should be calculated by Excel, then calculate the geometric average value, and finally calculate the weight. Calculating the maximum eigenvalue $\lambda \max$ of the judgment matrix $\mathrm{A}$ and its corresponding eigenvector $\omega=(\omega 1, \omega 2, . . \omega n) T$. $T$ after normalization, and 
when $A \omega=\lambda \max$, the obtained feature vector $\omega$ will become the weight vector of the corresponding evaluation unit ${ }^{[5]} . \lambda \max$ and $\omega$ can be calculated by power method and the square root method. The table below is calculated by the square root method. As shown in Table III.

TABLE III. EXAMPLE OF CALCULATING WEIGHT OR CRITERIA OF JUDGMENT MATRIX

\begin{tabular}{|c|c|c|c|c|c|c|}
\hline & B1 & B2 & B3 & B4 & Geometric Average Value & $\begin{array}{c}\text { Weight or } \\
\text { Criteria }\end{array}$ \\
\hline B1 & 1 & 7 & 5 & 3 & $\begin{array}{c}\sqrt[4]{1^{*} 7^{*} 5^{* 3}} \\
=3.2011\end{array}$ & $\begin{array}{c}3.2011 \\
/ 5.8786 \\
=0.5445\end{array}$ \\
\hline B2 & $1 / 7$ & 1 & $1 / 3$ & $1 / 5$ & $\begin{array}{c}\sqrt[4]{1 / 7 * 1 * 1 / 3 * 1 / 5} \\
=0.3124\end{array}$ & $\begin{array}{c}0.3124 / 5.8786 \\
=0.0531\end{array}$ \\
\hline & $1 / 5$ & 3 & 1 & $1 / 3$ & $\begin{array}{c}\sqrt[4]{1 / 5 * 3 * 1 * 1 / 3} \\
=0.6687\end{array}$ & $\begin{array}{c}0.6687 \\
/ 5.8786 \\
=0.1138\end{array}$ \\
\hline B3 & $1 / 3$ & 5 & 3 & 1 & $\begin{array}{c}\sqrt[4]{1 / 3 * 5 * 3 * 1} \\
=1.4953\end{array}$ & $\begin{array}{c}1.4953 \\
=0.8786\end{array}$ \\
\hline B4 & $1 / 2544$ \\
\hline$\sum$ & & & & & 5.8786 & \\
\hline
\end{tabular}

\section{2) Consistency check on the judgment matrix}

When testing whether the judgment matrix has satisfactory consistency, it is necessary to compare $C I$ with average random consistency index $R I$. $C I$ is consistency index, $R I$ is random consistency index, and the consistency formula is $C R=C I / R I$. The specified corresponding values of $R I$ are shown in Table IV. and the test coefficient $C R$ can be obtained. If $C R$ is $<0.1$, the judgment matrix is considered to pass consistency check, otherwise it will not have satisfactory consistency.

TABLE IV. The Average Random CONSISTENCy IndeX VALUE of THE 1-9 ORDER MATRIX

\begin{tabular}{|c|c|c|c|c|c|c|c|c|c|}
\hline Order & $\mathbf{1}$ & $\mathbf{2}$ & $\mathbf{3}$ & $\mathbf{4}$ & $\mathbf{5}$ & $\mathbf{6}$ & $\mathbf{7}$ & $\mathbf{8}$ & $\mathbf{9}$ \\
\hline RI & 0.00 & 0.00 & 0.58 & 0.90 & 1.12 & 1.24 & 1.32 & 1.41 & 1.45 \\
\hline
\end{tabular}

3) Procedure of Consistency Check

(1) To calculate consistency index $C I=(\lambda \max -n) /(n-1)$

(2) To query the $R I$ value according to the average random consistency index value table of the matrix.

(3) Calculate consistency ratio $C R=C I / R I$.

When $C R<0.1$, it means that the total ranking of the hierarchy had passed Consistency Check. Firstly, the maximum is calculated eigenvalue $\lambda \max$ of the judgment matrix, as in $\lambda \max =\sum_{i=1}^{n} \frac{(a \omega) i}{n \omega i}$ then $A \omega$ is calculated according to the Table IV and get $\lambda \max =4.12$.Thus, $C I=0.04, C R=$ $0.04<0.1$, the matrix meets consistency requirements. We can get the conclusion, that is, the relative importance weight in the target layer of B1, B2, B3 and B4 in the judgment matrix $\mathrm{A}$ are respectively $0.5445,0.0531,0.1138,0.2544$. AS Table III is shown. According to the above mentioned, the importance order of two program layers to the overall goal is B1 $>$ B4 $>$ B3 $>$ B2 successively. Therefore, teachers' teaching methods choice largely depends on students' knowledge understanding and learning ability. According to the above methods and procedures, the two-to-two judgment matrices of each index corresponding to scheme layer $\mathrm{C} 1$ and $\mathrm{C} 2$ can be constructed by analogy. The specific conclusions are shown in Tables V,VI,VII and VIII .

TABLE V. KNOWLEDGE COMPREHENSION

\begin{tabular}{|c|c|c|}
\hline & $\begin{array}{c}\text { Micro-course } \\
\text { Teaching }\end{array}$ & $\begin{array}{c}\text { Traditional } \\
\text { Teaching }\end{array}$ \\
\hline Micro-course Teaching & 1 & $1 / 3$ \\
\hline Traditional Teaching & 3 & 1 \\
\hline
\end{tabular}

TABLE VI. KNOWLEDGE EXTENSION

\begin{tabular}{|c|c|c|}
\hline & $\begin{array}{c}\text { Micro-course } \\
\text { Teaching }\end{array}$ & $\begin{array}{c}\text { Traditional } \\
\text { Teaching }\end{array}$ \\
\hline Micro-course Teaching & 1 & $1 / 3$ \\
\hline Traditional Teaching & 3 & 1 \\
\hline
\end{tabular}

TABLE VII. TEACHER-STUdENT MUtUAL COMMUNICATION

\begin{tabular}{|c|c|c|}
\hline & $\begin{array}{c}\text { Micro-course } \\
\text { Teaching }\end{array}$ & $\begin{array}{c}\text { Traditional } \\
\text { Teaching }\end{array}$ \\
\hline Micro-course Teaching & 1 & 3 \\
\hline Traditional Teaching & $1 / 3$ & 1 \\
\hline
\end{tabular}

TABLE VIII. LEARNING ABILITY

\begin{tabular}{|c|c|c|}
\hline & $\begin{array}{c}\text { Micro-course } \\
\text { Teaching }\end{array}$ & $\begin{array}{c}\text { Traditional } \\
\text { Teaching }\end{array}$ \\
\hline Micro-course Teaching & 1 & 3 \\
\hline Traditional Teaching & $1 / 3$ & 1 \\
\hline
\end{tabular}

Because the criterion layers (B1, B2, B3, B4) constructed are two-order matrices compared with the judgment matrix of scheme layers $(\mathrm{C} 1, \mathrm{C} 2)$, so they meet the requirements of Consistency Check and own satisfactory consistency.

\section{E. Total weight/criteria and hierarchy total ranking in evaluation indicators of micro-course teaching and traditional teaching}

The ranking for calculating relative importance of all factors at the same layer to the higher layer (total goal) is called hierarchical general ranking, which is carried out from the highest layer to the lowest layer by layer. Generally, adopting simple method to calculate (it is determined by the product of the weight value of a certain level index in a single layer and the weight of its corresponding higher level index in a single layer), the final weight value of each level index in the evaluation index system can be obtained ${ }^{[6]}$, as shown in Equation (1).

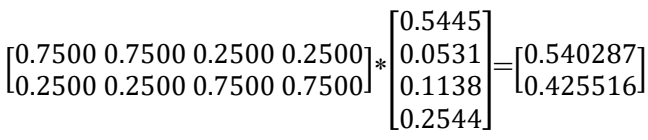

The result of hierarchical total ranking is $C 1>C 2, C 1$ is micro-course teaching, and $C 2$ is the analysis of traditional teaching evaluation results. Through AHP calculation, students generally believe that micro-course teaching is 
superior to traditional teaching, and micro-course teaching owns advantages in knowledge extension and learning ability.

\section{MICRO-COURSE TEACHING AND TRADITIONAL TEACHING}

Although micro-course teaching methods are widely applied in the field of education, and students' interest and learning ability have been improved, micro teaching can not be the only way for teachers. From the students' questionnaire, we can see that the traditional teaching can't be abandoned. At the same time, There are many advantages for the traditional teaching. The micro-course teaching should keep up with the development of the times, meet the requirements of students and make constant progress.

\section{A. Micro-course teaching}

Micro-course teaching is widely used in the field of education, which improves students' interest and learning ability, mainly reflected in the following four aspects ${ }^{[7]}$ :

\section{1) Individualized learning}

For students, micro-course teaching method can provide different knowledge points and they can choose course according to their needs. Micro-course teaching is a studentcentered personalized learning mode, its core, which can not only find out lack in knowledge and make up for the deficiency, but also strengthen and consolidate knowledge. At the same time, Micro-course is also a kind of extension of traditional classroom.

\section{2) Low resource capacity}

The resource capacity of micro-course teaching method is small, so it is convenient for teachers and students to watch micro-videos on mobile devices anytime and anywhere to carry out fragmentation learning, which can provide a great help to students' learning and ability improvement, and improve their learning initiative and interest.

\section{3) Improving teachers' professional quality}

For teachers, micro-course teaching is one of the ways for teachers to innovate traditional teaching methods and research models, and it is also one of the ways for teachers to break through traditional teaching mode and improve their professional knowledge and literacy. Teachers make use of their professional ability to produce a large number of excellent teaching resources, to achieve the sharing of teaching resources among teachers.

\section{4) Short but forceful}

The time of micro-course teaching is short, which conforms to cognitive characteristics and learning rules of students in primary and middle school, and improves the learning efficiency of students. Generally, micro-course does not exceed 10 minutes, and 5-8 minutes is suitable. The content is mainly focused on teaching focuses and difficulties, so that students can master knowledge. Micro-course video is very compact and easy to understand, and has been favored by many students.
However, there are many shortcomings in micro-course, such as the shortage of video resources and the low quality of resources, the limit use of micro-courses teaching and the lack of interaction between teachers and students .

\section{B. Traditional teaching}

With the rapid development of information technology and network technology, traditional teaching still has its value.

1) Knowledge is imparted in many ways

The traditional teaching is teacher-led and textbookcentered, and the emphasis is on teacher's teaching. A teacher faces to many students in class, which can expand the scope of teacher's knowledge transmission. At the same time, the cost of traditional teaching is low and relatively economical.

\section{2) Clear teaching objectives}

Teachers prepare teaching content purposefully, and ensure learning activities step by step every day. At the same time, students can make effective combination of listening and memorizing, which can attract students' attention and improvement of students' thinking ability and level, and ensure students can acquire more systematic, complete and solid knowledge.

\section{3) More Interaction between teachers and students}

Face-to-face teaching and learning can enable teachers and students to communicate constantly in the classroom, and enhance the emotions. Traditional teaching also can ensure teachers' leading role in teaching. Teacher and student communication can improve students' interest in learning, and motivate students' enthusiasm for learning.

\section{4) Promoting all-round development of students}

On the basis of implementing teaching tasks, traditional teaching can make teachers and students communicate in terms of student's moral, intellectual, physical and beauty in class. At the same time, activities can help students develop in all aspects.

\section{CONCLUSION}

By calculation of each judgment matrix in analytic hierarchy process, all matrix satisfy consistency check. The order of the total level is $\mathrm{C} 1>\mathrm{C} 2$, which it means that the teaching efficiency of micro-course is better than that of traditional teaching. It is not difficult to conclude that the effect of micro-course teaching is better than that of traditional teaching. Micro-course teaching method has been favored by most teachers and students, which can improve teaching efficiency and learning effect, but the teacher-student communication of traditional teaching is still a important factor in students' learning. Therefore, micro-course teaching is a useful complement to traditional teaching. Teachers can choose appropriate teaching methods according to specific circumstances and the students' situation. Only when microteaching and traditional teaching are effectively integrated together, they can play their advantages and positive role. 


\section{REFERENCES}

[1] National Program for Medium and Long-term Educational Reform and Development (2010-2020) .

[2] Saaty T L. Modeling unstructured decision problems - the theory of analytical hierarchies [J].Mathematics \& Computers in Simulation, 1978, 20 (3): 147-158.

[3] Li Jia Hou. Implication and Development of Micro-course[J]. Information Technology Education in Primary and Middle School, 2013 (4): $10-12$.

[4] Wang Zhao, He Bin, Zhu Zhiting. Micro Video Course: Evolution, Orientation and Application Fields [J]. China Audiovisual Education, 2013 (4): 88-94.

[5] Zhang Bingjiang. Analytic Hierarchy Process (AHP) and Application Case [M]. Electronic Industry Press, 2014.

[6] Wang Zeying, Zhao Qisi. System Establishment of Micro-course Evaluation Index Based on Analytic Hierarchy Process (AHP) [J]. Software Guide (Educational Technology), 2015 (7): 81-82.

[7] Zhang Xiaoqiao, Guo Gensheng. Elementary Analysis of Advantage and Complementary Relationship Between Network Teaching and Traditional Teaching [J]. Audiovisual Education Research, 2008 (2): 8991. 